\title{
Conception of a YBCO Superconducting ZFC-Magnetic Bearing Virtual Prototype
}

\author{
A.J. Arsénio, M.V. Carvalho, C. Cardeira, \\ P.J. Costa Branco \\ IDMEC, Instituto Superior Técnico, Universidade de \\ Lisboa, Lisbon, Portugal
}

\author{
R. Melício \\ IDMEC, Instituto Superior Técnico, Universidade de \\ Lisboa; Departamento de Física, Escola de Ciências e \\ Tecnologia Universidade de Évora, Portugal
}

\begin{abstract}
This paper presents the conception of an original superconducting Frictionless Zero Field Cooling bearing virtual prototype. In previous work also shown in this conference, a viability study of a Zero Field Cooling-superconducting bearing concept was conducted. It showed that the virtual prototype is feasible. Moreover, the simulation studies showed that a Zero Field Cooling superconducting track provides not only effective lateral stability but also higher levitation forces than the commonly used Field Cooling tracks. In this paper the new Zero Field Cooling -bearing virtual prototype is modeled in 3D. The virtual prototype was designed having in mind: i) a future implementation in high density polyurethane, for low temperature robustness; ii) future manufacturing in a three axes CNC milling machine and; iii) future implementation of some parts using an additive manufacturing technique.
\end{abstract}

Keywords-High-temperature superconductors; bearings; magnetic levitation; virtual prototype; $\mathrm{YBCO}$; $Z F C$.

\section{INTRODUCTION}

Superconductivity is the phenomenon of certain materials exhibiting zero electrical resistance and the expulsion of magnetic fields under specific temperature, magnetic field and current conditions. Each superconducting material has an absolute critical temperature above which it loses its superconducting properties [1].

When type II superconductor bulks are cooled in the absence of any magnetic fields, known as the Zero Field Cooling (ZFC) technique, the trapped flux density is almost null [1]. In this case, when they are positioned in the middle of an existing magnetic field they are repealed to a position where the magnetic flux is nearly zero. Hence namely levitation systems can be ZFC or Field Cooled (FC) [1].

A well-known application of superconductor levitation is on the construction of superconductor magnetic bearings (SMB) [2]. Compared to the usual bearings, these new kind of bearings present significant advantages in terms of friction, weariness and maintenance. Nevertheless, they present the throwback of continuous superconductors refrigeration.

Most of the existing levitation systems use permanent magnets (PM) on one part and type II superconductor bulks on the other part. Frictionless rotating bearings are sub-divided onto horizontal axis rotating systems in which the levitation forces are radial and vertical axis rotating systems in which the levitation forces are axial to a vertical axis [1]. Some horizontal or vertical axis rotating systems based on levitation forces are shown in Table I [3-6].

The main contribution of this paper is to design a real prototype of an original SMB.

TABLE I. ROTATING SySTEMS BASED ON LEVITATION ForCES

\begin{tabular}{|c|c|c|c|c|c|}
\hline Axis & Use & $\begin{array}{c}\text { Angular } \\
\text { speed } \\
\text { (rpm) }\end{array}$ & Stator & Rotor & Reference \\
\hline Horizontal & Flyweel & 40000 & $\begin{array}{c}\text { NdFeB } \\
\text { PM }\end{array}$ & $\begin{array}{c}\text { YBCO } \\
\text { bulks }\end{array}$ & {$[3]$} \\
\hline Vertical & Flyweel & 4000 & $\begin{array}{c}\text { YBCO } \\
\text { bulks }\end{array}$ & $\begin{array}{c}\text { NdFeB } \\
\text { PM }\end{array}$ & {$[4]$} \\
\hline Horizontal & $\begin{array}{c}\text { HTS } \\
\text { motor }\end{array}$ & 1500 & YBCO & $\begin{array}{c}\text { NdFeB } \\
\text { PM }\end{array}$ & {$[5]$} \\
\hline Horizontal & Flyweel & 15860 & YBCO & $\begin{array}{c}\text { PM } \\
\text { rings }\end{array}$ & {$[6]$} \\
\hline
\end{tabular}

This paper is organized as follows: Section II presents the previously work made simulations of the SMB. Section III shows the virtual prototype design detailing the 3D model of the projected SMB. In Section IV some conclusions are drawn.

\section{PREVIOUS WORK}

In previous work $[7,8]$, an original ZFC Maglev vehicle was proposed, simulated and tested. Using similar principles, an original SMB was projected and simulated. It was shown the viability of a ZFC frictionless SMB. The projected ZFC SMB outperforms the commonly used FC technique. The simulation showed that, with a given geometry and air gap dimensions, a ZFC SMB is viable and feasible.

This paper presents the conception of a virtual prototype of the simulated SMB. In particular, this virtual prototype should provide a structure to put in place $\mathrm{N} 40 \mathrm{NdFeB}$ PMs and ZFC High Temperature Superconductors (HTS).

The detailed geometry and dimensions of the SMB prototype, which meet the geometry and dimensions of the simulated SMB, are shown in Fig. 1.

Fig. 1 shows $16(2 \times 8)$ HTS in the SMB stator and $15(3 \times 5)$ $\mathrm{PM}$ in the SMB rotor. 
The perspective view of the SMB with the magnetization directions and contours is shown in Fig. 2.
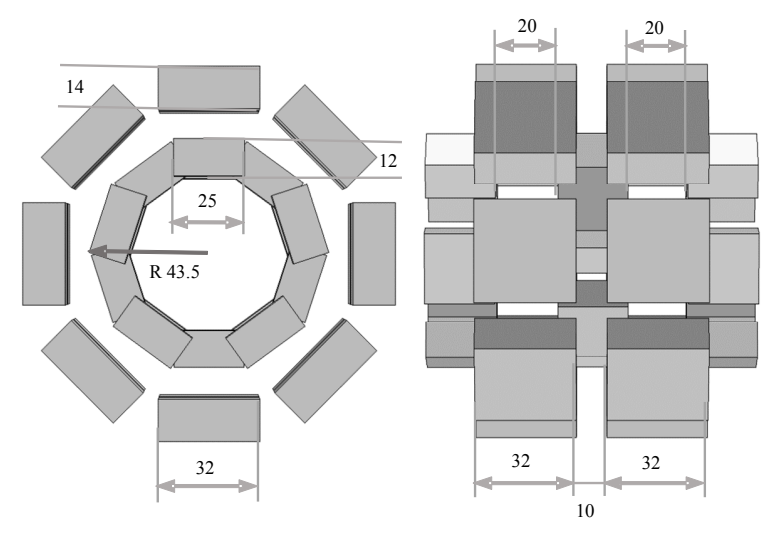

Figure 1. Detaild geometry and dimensions of the SMB prototype.

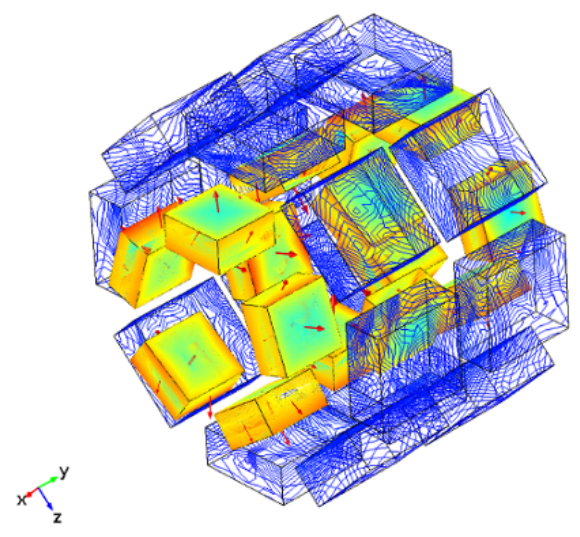

Figure 2. Perspective view of magnetization directions and contours.

The transversal view of the SMB with the magnetization directions and contours is shown in Fig. 3.

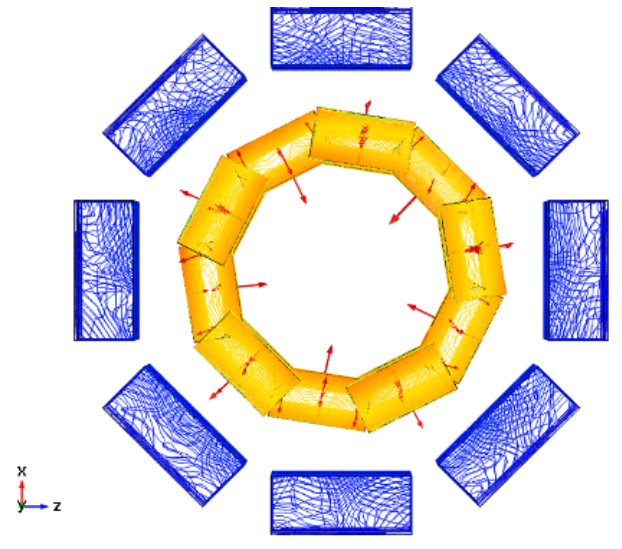

Figure 3. Transversal view of magnetization directions and contours.

In Fig. 2 and in Fig. 3, the dimensions of each HTSs are $32 \times 32 \times 14 \mathrm{~mm}$, and the dimensions of each PM are $25 \times 25 \times 12$ mm. All of HTSs and PMs are combined in a structure defined in [1].

In [1] it was shown that: the levitation and guidance forces for a $10 \mathrm{~mm}$ air gap were $11.02 \mathrm{~N}$ and $11.96 \mathrm{~N}$, respectively.

The axial forces for a translation between $2 \mathrm{~mm}$ and $8 \mathrm{~mm}$ and the air gap of $10 \mathrm{~mm}$ are shown in Table II.

TABLE II. AXIAL FORCES FOR A TRANSLATION

\begin{tabular}{|c|c|c|c|c|}
\hline \multicolumn{5}{|c|}{ Air gap 10 mm } \\
\hline Translation & $\mathbf{2}$ & $\mathbf{4}$ & $\mathbf{6}$ & $\mathbf{8}$ \\
$(\mathbf{m m})$ & $(\mathbf{m m})$ & $\mathbf{( m m )}$ & $(\mathbf{m m})$ \\
\hline $\begin{array}{c}\text { Axial force } \\
\text { (N) }\end{array}$ & 3.45 & 6.81 & 9.18 & 10.84 \\
\hline
\end{tabular}

The radial forces for an eccentricity between $2 \mathrm{~mm}$ and $8 \mathrm{~mm}$ and the air gap of $10 \mathrm{~mm}$ are shown in Table III.

TABLE III. RADIAL FORCES FOR AN ECCENTRICITY

\begin{tabular}{|c|c|c|c|c|}
\hline \multicolumn{5}{|c|}{ Air gap 10 mm } \\
\hline Eccentricity & $\begin{array}{c}\mathbf{2} \\
(\mathbf{m m})\end{array}$ & $\begin{array}{c}\mathbf{4} \\
(\mathbf{m m})\end{array}$ & $\begin{array}{c}\mathbf{6} \\
(\mathbf{m m})\end{array}$ & $\begin{array}{c}\mathbf{8} \\
(\mathbf{m m})\end{array}$ \\
\hline $\begin{array}{c}\text { Radial force } \\
\text { (N) }\end{array}$ & 6.19 & 12.79 & 24.11 & 39.46 \\
\hline
\end{tabular}

Table II and Table III show that the viability of the superconductor magnetic bearing prototype.

\section{PRototype DESIGN}

The use of 3D CAD Design Software for concept design has been widely spread. Moreover, CNC machines are nowadays able to produce real prototypes based on the $3 \mathrm{D}$ CAD designed models. Lately, additive manufacturing techniques like 3D printers became more and more used for rapid prototyping [9].

Hence, a SMB prototype was modelled in 3D CAD Design Software SOLIDWORKS to meet the following requirements: i) provide a structure to keep the distances, relative positions and the air gap of the HTSs and PMs [1]; ii) provide a way to cool the HTSs with liquid nitrogen; iii) develop a modular prototype; iv) design a prototype with easy assembly and disassembly features for practical PMs and HTSs accessibility, maintenance and/or replacement.

Three main blocks were designed for the SMB: the stator, which is the outer part of the SMB; the rotor, which is the inner rotating part of the SMB; some fasteners to keep the structure together.

\section{A. Stator}

The outer part of the SMB is the stator, does not move and supports 16 HTSs distributed in two rings as projected in Fig. 1. The model of one stator slice with 8 HTSs bulks is shown in Fig. 4. 
Identical slices that can be assembled to produce the whole SMB stator, i.e., the stator exploded view is shown in Fig. 5.

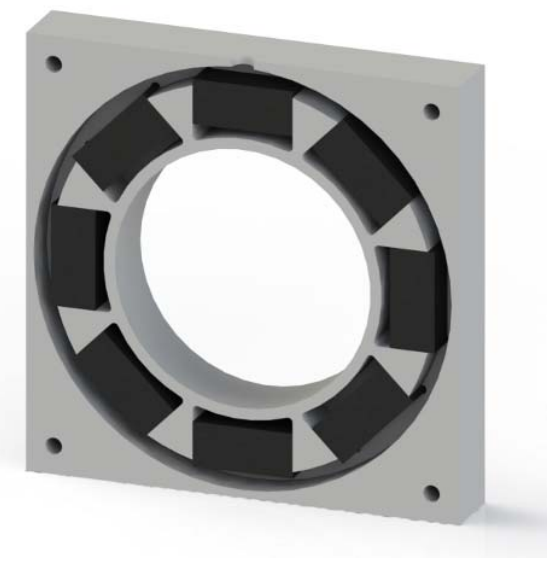

Figure 4. One stator slice with HTSs bulks.

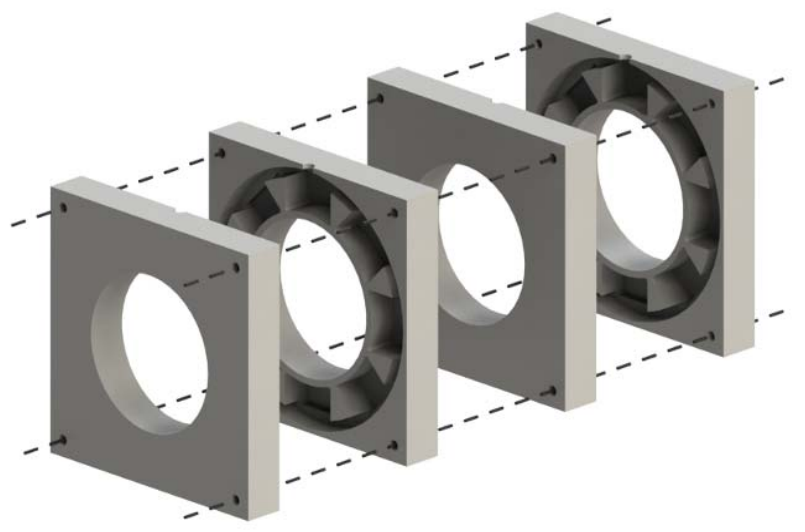

Figure 5. Stator exploded view.

In Fig. 5, 2 symmetric profiles of 8 cavities each are shown, where the HTSs are to be positioned.

This model (Fig. 5) guarantees the distance and relative positions of the HTSs. All of these cavities are connected through a channel, so that liquid nitrogen can flow and cool the HTSs. The prototype is modular, namely because of the construction based on slices, that allows multiple configurations. This type of construction also eases the assembly and disassembly of the prototype. For the purpose of joining the assemblies together, 4 holes of $6 \mathrm{~mm}$ diameter were projected. For future implementation purposes, it is expected that the stator will be built in a material that must resist to $77 \mathrm{~K}$ operation. Hence the stator will be built using some sort of polyurethane.

\section{B. Rotor}

The inner part of the SMB is the rotor. It is the rotating part of the SMB and supports 15 PMs distributed in three rings as presented in Fig. 1. The exterior rotor slice with 5 PMs in place is shown in Fig. 6.

The interior rotor slice with 5 PMs in place is shown in Fig. 7.

The complete rotor, i.e., the rotor exploded view is shown in Fig. 8.

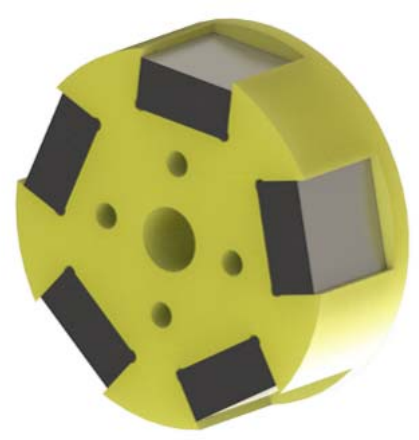

Figure 6. Exterior rotor slice with PMs.

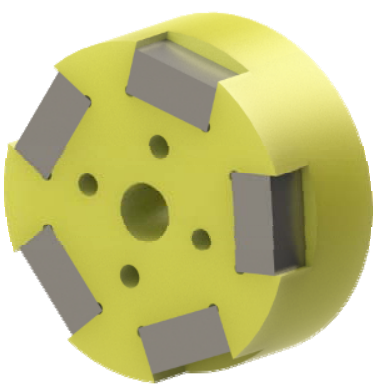

Figure 7. Exterior rotor slice with PMs.

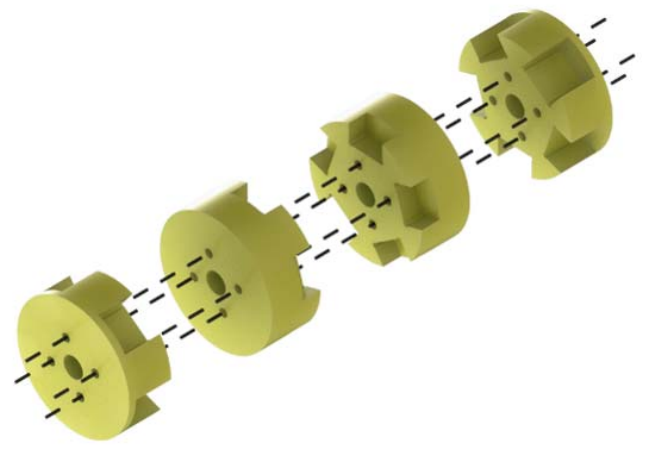

Figure 8. Rotor exploded view. 
In Fig. 8, the rotor exploded view is composed by 2 interior and 2 exterior slices assembled to produce the final type part. This type of slice construction was used to make possible a manufacturing in a CNC milling machine.

The model (Fig. 8) guarantees the distance and relative positions of the PMs. There is no need of liquid nitrogen channels because the rotor does not need to be cooled. Like the stator, the rotor prototype is modular, namely because of the construction based on slices, that also allows multiple configurations. This prototype modular type of construction eases the assembly and disassembly. For the purpose of joining the assemblies together, 4 holes of $6 \mathrm{~mm}$ diameter were projected.

\section{Fasteners}

Some fasteners were projected, namely bolts, nuts, corners and washers to assemble the SMB parts together. Special care was taken in the modelling of these parts. As polyurethane has limited mechanical resistance, the miscellaneous parts were modeled to carefully keep the parts assembled without hurting the delicate material. These miscellaneous parts have no special requirements besides being transparent to the magnetic field and exhibit low thermal conductivity to keep the stator cooled. Hence, it seems that it will be possible to make them using additive manufacturing, namely, a normal 3D printer.

\section{Bolts}

To keep the rotor slices together, hexagonal head bolts with a diameter of $6 \mathrm{~mm}$ and a length of $150 \mathrm{~mm}$ were designed. The bolt is shown in Fig. 9.

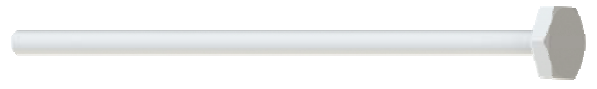

Figure 9. Bolt with a diameter of $6 \mathrm{~mm}$ and a length of $150 \mathrm{~mm}$.

To keep the stator slices together, hexagonal head bolts with a diameter of $6 \mathrm{~mm}$ and a length of $115 \mathrm{~mm}$ were designed. The bolt is shown in Fig. 10.

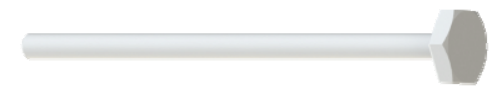

Figure 10. Bolt with a diameter of $6 \mathrm{~mm}$ and a length of $115 \mathrm{~mm}$.

\section{Nuts}

For all bolts, eight nuts were built to assemble both stator and rotor together. The nut is shown in Fig. 11.

Nuts threads and bolts threads were not designed because it is assumed that they will be printed on a $3 \mathrm{D}$ printer, which normally does not have enough resolution to print the threads. Hence it is assumed that the threads will be made manually.

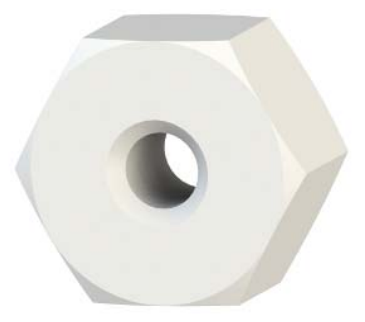

Figure 11. Nuts.

\section{Stator corners}

As the stator material is expected to be soft and fragile, eight corners were modelled to increase the surface of contact, reducing the pressure applied to the material by the bolts. One corner is shown in Fig. 12.

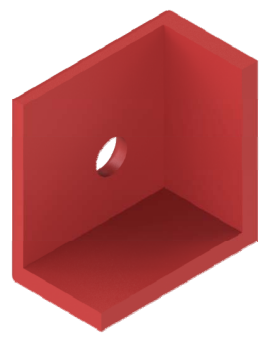

Figure 12. Stator corner.

\section{Rotor washers}

The rotor material does not need to resist to such low temperatures, because the PMs do not need to be cooled. Nevertheless, assuming that the rotor might also be constructed with the same materials of the stator, two washers were modelled to increase the surface of contact. One washer is shown in Fig. 13.

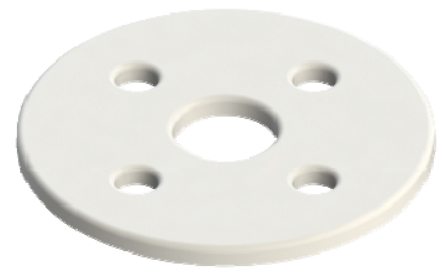

Figure 13. Rotor washer.

\section{Fasteners complete set}

The set of the fasteners used for the final assembly of the $\mathrm{SMB}$ is shown in Fig. 14. 


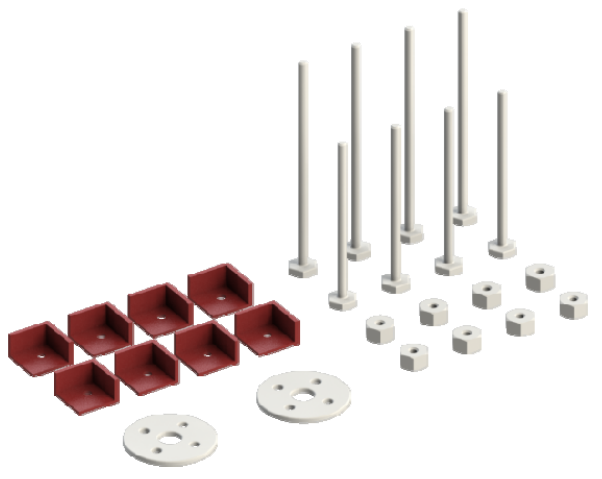

Figure 14. SMB, fasteners for final assebly.

\section{Virtual Assembly of the Prototype}

With the components modelled before, the SMB was assembled according to the exploded view shown in Fig. 15.

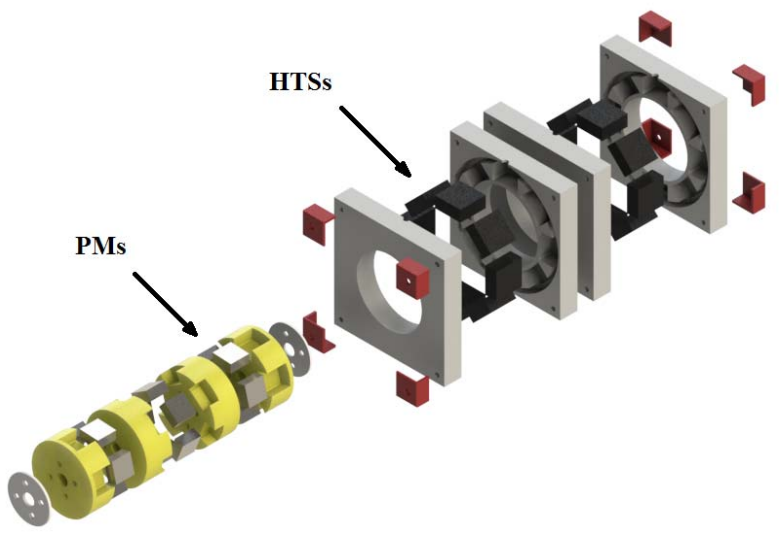

Figure 15. SMB exploded view.

The SMB virtual prototype final assembly view is shown in Fig. 16.

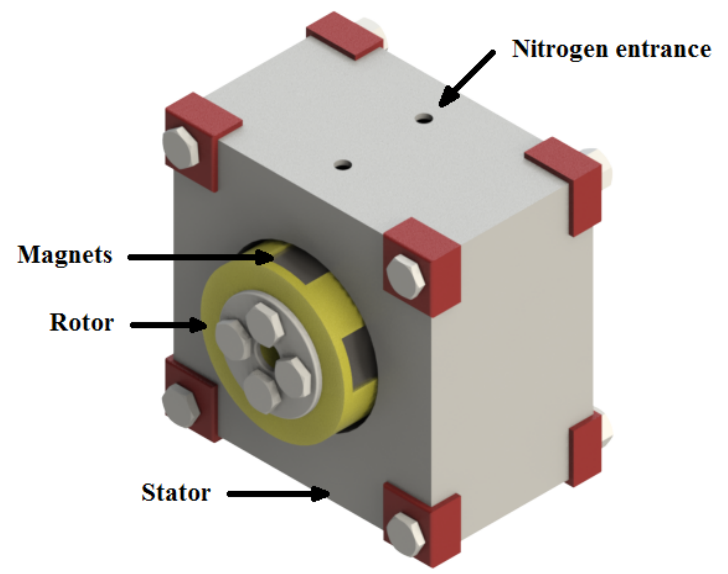

Figure 16. SMB final assembly view.

\section{CONCLUSIONS}

In this paper a prototype of an original previously simulated SMB was modelled using a 3D CAD Design Software. The prototype was designed to keep the same geometry and dimensions of the previously simulated SMB. The prototype was modelled in several slices, to take into account that the real SMB could be manufactured using a CNC 3 axes milling machine. Special care was taken in the modelling of the miscellaneous parts to keep the model assembled without hurting the delicate stator materials. Future work will be the implementation of the real prototype. A correct choice of materials as well as of the manufacturing techniques has to be performed. Moreover, additional tests of the real prototype resistance against low temperatures and leak tests will be carried out. Finally, the effectiveness of the real SMB against the simulations previously made will be performed to validate the complete design.

\section{ACKNOWLEDGMENT}

This work is funded by support of fellowship EMS/50022 granted by IDMEC/LAETA to A.J. Arsénio, as researcher in this R\&D Institution and as $\mathrm{PhD}$ Student at Instituto Superior Técnico, Universidade de Lisboa, Portugal; and by Portuguese Funds through the Foundation for Science and TechnologyFCT under the project LAETA 2015 - 2020, reference UID/EMS/50022/2013.

\section{REFERENCES}

[1] A.J. Arsénio, M.V. Carvalho, C. Cardeira, R. Melício, and P.J. Costa Branco, "Viability of a frictionless bearing with Permanent Magnets and HTS bulks," in Proc. 17th IEEE International Conf. on Power Electronics and Motion Control-PEMC, pp. 1-6, September 2016.

[2] Moon, Francis C. Superconducting Levitation: Applications to Bearing and Magnetic Transportation. John Wiley \& Sons, 2008.

[3] T.H. Sung, S.C. Han, J.S. Lee, N.H. Jeong, S.D. Hwang, and S.K. Choi, "Designs and analyses of flywheel energy storage systems using high- $\mathrm{T}_{\mathrm{c}}$ superconductor bearings," Cryogenics, vol. 42, pp. 357-362, 2002.

[4] Y.H. Han, B.J. Park, S.Y. Jung, and S.C. Han, "Study of superconductor bearings for a $35 \mathrm{kWh}$ superconductor flywheel energy storage system," Physica C: Superconductivity, vol. 483, pp. 156-161, 2012.

[5] P. Kummeth, W. Nick, and H.-W. Neumueller, "Progress in development of high capacity magnetic HTS bearings," Physica C: Superconductivity, vol. 426-431, pp. 739-745, October 2005.

[6] J. Zheng, Z. Deng, L. Wang, L. Liu, Y. Zhang, S. Wang, and J. Wang, "Stability of the maglev vehicle model using bulk high $\mathrm{T}_{\mathrm{c}}$ superconductors at low speed," IEEE Transactions on Applied Superconductivity, vol. 17(2), pp. 2103-2106, June 2007.

[7] P.J. Costa Branco, and J.A. Dente, "Design and experiment of a new maglev design using zero-field-cooled YBCO superconductors," IEEE Transactions on Industrial Electronics, vol. 59(11), pp. 4120-4127, November 2012.

[8] J. Fernandes, I. Montes, R. Sousa, C. Cardeira, and P.J. Costa Branco, "Superconductor joule losses in a zero-field-cooled (ZFC) maglev vehicle," IEEE Transactions on Applied Superconductivity, vol. PP(90), pp. 1-7, February 2016.

[9] K. Bassett, R. Carriveau, and D.S.-K. Ting, "3D printed wind turbines part 1: design considerations and rapid manufacture potential," Sustainable Energy Technologies and Assessments, vol. 11, pp. 186193, September 2015. 